\title{
Next Wave of e-Government in Hong Kong - Steering Committee Report and Interview with Chief Information Officer
}

The e-Government Steering Committee (EGSC) was set up by the Hong Kong government in 2004 and chaired by the Financial Secretary. It has a mission to steer the further development of e-Government programs and approves measures to facilitate the implementation of the program. Since its establishment, the EGSC had considered and endorsed the vision, mission and key priorities of the next wave of e-Government as well as provided policy steering for a number of eGovernment initiative. The EGSC recently published its vision of the next wave of e-Government to: use IT to provide customer-centric services that promote accessible, accountable and efficient government and contribute to Hong Kong's achievement as a leading digital city. (www.info.gov.hk/digital21).

It mission, as defined by EGSC is:

To serve the community by providing integrated one-stop and customer centric e-services that deliver increased value and facilitate better access to public services,

To transform the Government by business process re-engineering that improves the delivery, strengthens the value of customer orientation and enhances efficiency and productivity.

To sustain Hong Kong as a leading digital city by promoting a more pervasive e-environment that raises the e-literacy of the community and by driving the adoption of e-commerce and e-business.

The next wave of e-Government emphasizes the need to adopt a top-down approach in driving e-Government initiatives. Top-level commitment from the heads of bureaus/departments in planning and implementing eGovernment initiatives as well as initiating the nec- essary changes in the organization, culture of business processes and internal resource allocation are of paramount importance.

\section{New Strategy for e-Government Services Delivery}

"The emerging trend is to provide e-services based on a clustered approach centered around the needs of customer segments, and make better and more flexible use of the private sector's experience, expertise and resources to develop and promote e-services.

We consider that our new e-business strategy should seek to achieve three overall objectives: first, to enhance the quality of e-Government services that boost their utilization through introducing customer segmentation and end-to-end processing. Second, allow more private sector participation so that the Government can better leverage their expertise and experience. Third, promote the adoption of e-Commerce and e-Business in Hong Kong through closer integration of public and commercial e-Services/transactions, thereby increasing the utility and convenience for the users.

Accordingly, the Government will adopt a service clustering approach for the future delivery of eGovernment services. Under this approach, related eGovernment services, each cluster will provide, where appropriate, related commercial services so as to enhance the customer and commercial value of the cluster. To maximize the value to the customer the service clusters will seek to provide services along the whole value chain (e.g. from application for travel documents to purchase of airline tickets and travel insurance) and adopt end-to-end processing approach (e.g. from e-booking/e-submission to e-payment). In order 
that the public can continue to access e-Government services in different clusters conveniently, we will consider setting up a one-stop access portal with linkages to various service clusters as the public interface, and the clusters will be reviewed from time to time to reflect customer demand and market dynamics.

As regards the technology infrastructure strategy, we will progressively evolve our technology architecture based on open and interoperable standards that support easy interfacing within Government and with the private sector. Specifically, a Service-Oriented Architecture, a design principle that focuses on clearly defined interfaces according to business rules and that best supports diverging IT environments of different service agents, will be adopted to facilitate service agents to develop front-end applications and connect them to the back-end systems in Government. Furthermore, common services (e.g. e-payment gateway) required by e-Government services using the infrastructure will be identified and provided to minimize duplication of resources in developing and providing such services. The new technology infrastructure strategy can cater for various combinations of clustering and interface options for joining up the e-services provided by the Government and the private sector."

\section{Customer Relationship Management (CRM)}

"Adoption of CRS principles in the delivery of e-Government services is key to the provision of customer-centric services. This is in line with the vision of the next wave of e-Government and an important building block of our new strategy for e-Government service delivery. To assist business and departments better understand customer needs and preferences and provide more customer-oriented e-Government services, we have promulgated a CRM Guide for reference by bureaus and departments."

\section{Channel Management Strategy}

"Government services are provided through different channels of service delivery (e.g. at the counter, by mail, phone, fax and via the Internet). However, without a long-term vision and strategy for channel management, the provision of e-option as an additional channel of service delivery, alongside the conventional channels will not bring about the desired benefits, such as increasing efficiency and reducing operating costs. Given that the e-channel is normally the most efficient strategy together with the necessary incentives will help migrate customers to the e-channel. Accordingly, we will promulgate a channel management strategy to provide bureaus and departments with guidelines on how to enhance the quality and attractiveness of e-services so as to boost their utilization, the introduction of incentives to migrate customers to the e-channel, the rationalization of service delivery channels and the scaling down of the more costly channels where possible and justified.

\section{Electronic Procurement}

"The considerable size of government procurement and its scale of activities present huge potential for eprocurement. The labor and management costs for administering these procurements are likely to be substantial.

With the aim of enhancing internal efficiency and driving the adoption of IT in the business sector, especially SMEs a consultancy study was completed mapping out a strategy for taking forward e-procurement in the Government A pilot program is under implementation in text our e-procurement at departmental level with a view to improve internal efficiency and encourage external suppliers, especially the SMEs to take on e-business."

\section{Measuring the Benefits of e-Government Initiatives}

"To ensure cost-effectiveness of e-Government IT investment, we see the need to putting in place enhanced measures to identify, quantify and measure the benefits attributable to e-Government projects. To this end, we have launched a consultancy study on Business Case for Government IT Investment. The study was completed in March 2007. A Management Guide is produced to promulgate the recommended processes, methodologies and tools to be used. The Guide will assist bureaus and departments in adopting the new framework for developing a business case."

\section{Interview with Howard Dickson, Chief Information Officer (CIO), Government of Hong Kong}

Interview conducted by eGovMonitor Newsdesk, with Howard Dickson, CIO in August 2008, to learn of the "successful approach to creating a vibrant and flourishing e-Government environment for e-Government innovation." 
Can your give us a brief overview of Hong Kong's approach and policy towards e-Government?

"Like most other economies, Hong Kong has focused on the development of legal and physical infrastructure and provision of e-options in the initial phase of e-Government development. By end of 2003, we have achieved the target of providing e-option for $90 \%$ (or 1,200 services) of the public services amenable to electronic mode of delivery. We have also launched a number of flagship e-Government projects such as the Electronic Service Delivery (ESD) scheme and the multi-applications smart identity card.

"With the establishment of the Office of the Government Chief Information Officer (OGCIO) and a high-level e-Government Steering Committee (EGSC), chaired by the Finance Secretary, in July and September 2004 we have entered into a new phase of eGovernment development.

"Our vision for the next wave of e-Government is to "use information technology to provide customercentric services that promote an accessible, accountable and efficient government and contribute to Hong Kong's achievement as a leading digital city.

\begin{abstract}
"Our mission is to:
serve the community by providing integrated onestop and customer-centric e-services that deliver increased value and facilitate better access to public services,

transform the Government by business process re-engineering that improves the service delivery, strengthens the value of customer orientation and enhances efficiency and productivity, and

sustain Hong Kong as a leading digital city by promoting a more pervasive e-Environment that raises e-Literacy of the community and driving the adoption of e-Commerce and e-Business."
\end{abstract}

The Office of the Government Chief Information Officer was created in 1994 to drive the e-Government process in Hong Kong. Can you give us an insight into your role as Hong Kong CIO?

"I see my role primarily as a champion of and facilitator in using e-Government to transform governmental businesses and processes, so as to make the HKSARG a more efficient and more responsive government and one providing citizen-centric services. The e-Government programs, coupled with successful collaboration with the private sector, would help increase the adoption of e-Commerce and e-Business in Hong Kong."

Can you provide a brief overview of the project approval and management process, and how this integrated approach has helped the development of e-government in Hong Kong?

"OGCIO has a central role in managing IT budget and investment across the Government. It manages a central fund for IT projects costing between HK\$ 150,000 and HK\$ 10 million. It also examines and where appropriate provides policy support for IT projects costing over HK\$ 10 million before individual departments seeking funding approval from the Finance Committee of the Legislative Council.

The availability of a central source of funds helps drive forward e-Government development. In recent years, we have successfully used this approach to introduce a number of common $\mathrm{G} 2 \mathrm{E} / \mathrm{G} 2 \mathrm{G}$ applications, a variety of e-Government services and generic departmental IT facilities."

Public-Private-Partnerships (PPP) are a key component of your e-Government and public sector ICT infrastructure program. Can you share your approach towards PPPs and how you have implemented them in some of your major projects?

"The Government recognizes the potential of PPP to exploit the best commercial skills, practices and disciplines to deliver high quality public services while maintaining a lean civil service and creating private sector opportunities.

In assessing the suitability of IT projects for PPP, the Government has to address a number of issues including the identification of a sound business case, determination of output-based performance specifications that encourage flexibility and innovation, a fair allocation of risks and responsibilities between the government and private sector, how to ensure transparency and encourage competition, and safeguarding the interests of the general public. We will examine the suitability of using the PPP model in the IT projects on a case-by-case basis, having regard to the above mentioned factors."

The Electronic Service Delivery (ESD) scheme is one of the key projects for Hong Kong e-Government. Tell us more about this.

"ESD provides an integrated, one-stop platform for the public to interact and transact with the Government electronically. It was launched in January 2001 and 
currently provides more than 200 e-Government services for the public. It is one of the world's first fully bilingual one-stop portals providing integrated public and commercial services.

ESD is characterized by its focus of customerorientation as reflected in the design of the user interface, integration of public and commercial services, diversity of electronic payment methods supported by strong measures of security and personal data protection adopted. ESD adopts an innovative PPP model. The private sector operator is responsible for developing, financial and operating and maintaining the ESD front-end application and infrastructure. The Government pays the operator only when a certain usage limit is exceeded. In return, the private sector operator is allowed to make use of the ESD infrastructure for advertisements and commercial services to generate additional income. Under this model the business risk of the Government is kept to the minimum while the private sector operator has continuous incentive to promote the wider use of ESD services and to introduce service enhancements."

\section{What will be your main priorities over the next few years and what do you perceive to be the main chal- lenge?}

"In the next few years, Hong Kong will be pursuing the following key priorities with respect to eGovernment:

Implement a new strategy for e-Government service delivery based on service clustering with an objective of driving up the utilization of e-Government services. We will work on a single destination site for existing online government services and content and progressively put in place a number of service clusters. We will also gradually open up e-Government services for the introduction of value-added services by the private sector.

Encourage government departments to adopt cus- tomer relationship management in delivering their eServices with a view to increasing customer satisfaction and take-up of e-Services.

Migrate customers to the e-Channel through the adoption of a channel management strategy by taking into account the cost-effectiveness of the different channels and customer preferences.

Explore opportunities for e-Procurement with a view to improving efficiency in procurement processes and delivering tangible results.

Enhance the current mechanism for identifying and measuring benefits of e-Government initiatives.

The main challenge is to join up bureaus/departments to delivery e-Services that can better meet the needs of individual customer segments. This will require transformation of not only the services and business processes, but also the mindset and culture at different levels of the government. We will have to develop sound and convincing business cases to move bureaus/departments beyond their silos to offer joined-up services to citizens."

\section{What insights and suggestions would you have for other Government CIOs in their respective coun- tries?}

"A CIO should try to avoid becoming too technology driven, as e-Government is ultimately more concerned with business transformation and re-engineering. I think the challenge we all face is how to transform the organization and make it citizen-centric. The approach that I think worth trying is to make your best efforts to understand the challenges and priorities of senior colleagues and see how you could help them resolve/attain new solutions and widgets. Unless they know that they are talking to somebody that understands their challenges, we will not earn their attention and confidence. Getting their attention is just the beginning. The next step is to work with them to resolve the issues." 